This item was submitted to Loughborough's Research Repository by the author.

Items in Figshare are protected by copyright, with all rights reserved, unless otherwise indicated.

\title{
Valve-train dynamics: a simplified tribo-elasto-multi-body analysis
}

PLEASE CITE THE PUBLISHED VERSION

PUBLISHER

Professional Engineering Publishing / @ IMECHE

VERSION

VoR (Version of Record)

LICENCE

CC BY-NC-ND 4.0

REPOSITORY RECORD

Kushwaha, M., Homer Rahnejat, and Z.M. Jin. 2019. "Valve-train Dynamics: A Simplified Tribo-elasto-multibody Analysis”. figshare. https://hdl.handle.net/2134/4803. 
This item was submitted to Loughborough's Institutional Repository (https://dspace.lboro.ac.uk/) by the author and is made available under the following Creative Commons Licence conditions.

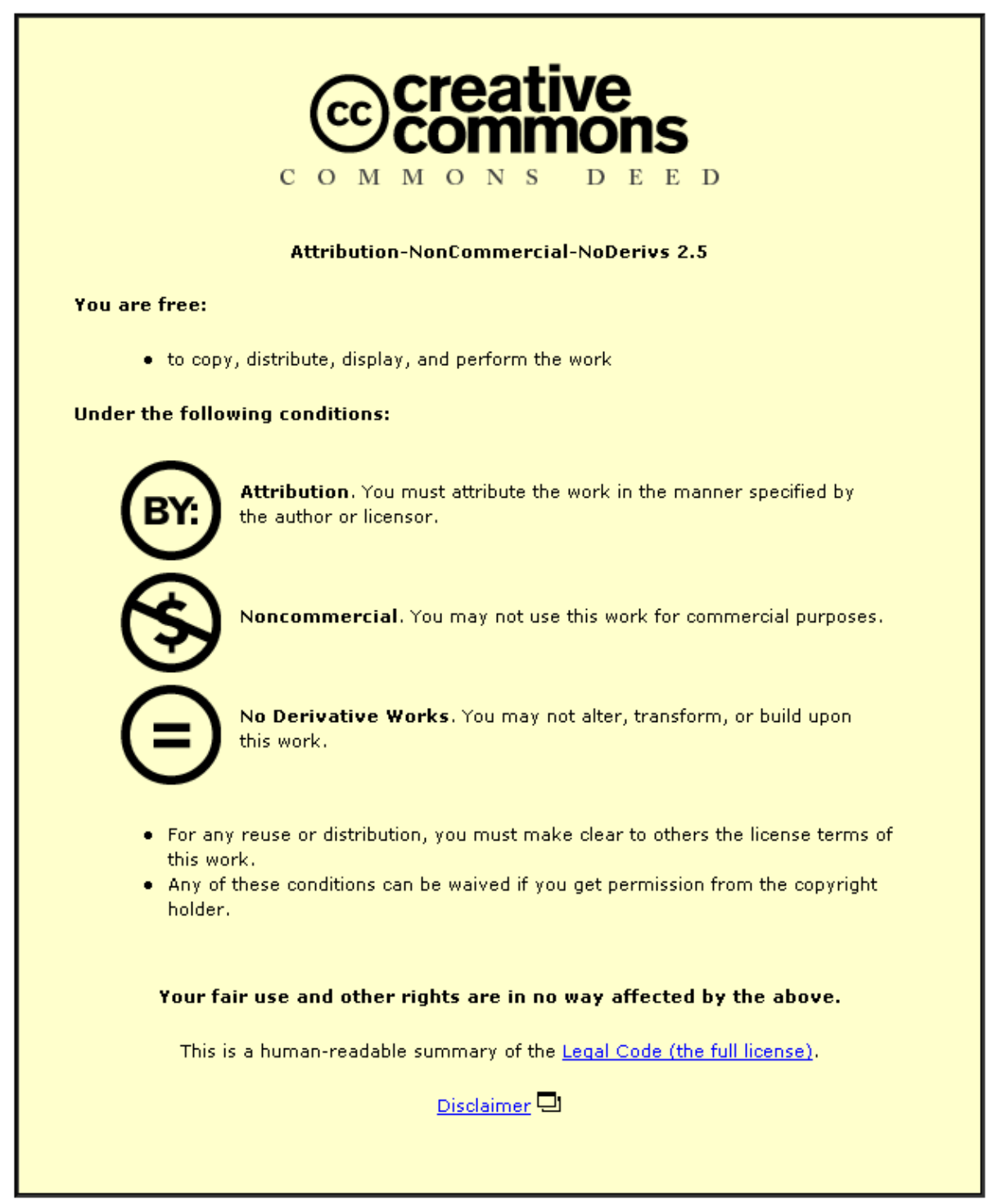

For the full text of this licence, please go to: http://creativecommons.org/licenses/by-nc-nd/2.5/ 


\title{
Valve-train dynamics: a simplified tribo-elasto- multi-body analysis
}

\author{
M Kushwaha, H Rahnejat* and Z M Jin \\ Department of Mechanical Engineering, University of Bradford, UK
}

\begin{abstract}
This paper presents a model of a cycloidal cam-flat follower pair. The model incorporates the inertial elements, the assembly constraint functions and the sources of compliance in the valve train. The sources of compliance include the valve spring characteristics, including the spring surge effect under dynamic conditions, as well as the contact compliance between the cam and the flat follower. The contact domain is treated as a counterformal concentrated lubricated region subjected to an elastohydrodynamic regime of lubrication (EHL). The prevailing contact geometry is one of finite line contact.

The paper presents the results of simultaneous solution of the Lagrangian dynamics for the non-linear constrained system, together with an approximate quasi-static elastohydrodynamic solution of the lubricated contact conjunction at each time step by an extrapolated oil-film thickness formula for combined entraining and squeeze film action. The effect of spring surge on the contact separation and residual vibrations of the system are investigated, as well as the lubricant pressure distribution and film thickness, including during start-up and acceleration.
\end{abstract}

Keywords: valve train dynamics, valve spring surge, elasto-multi-body dynamics

$\begin{array}{ll}\text { NOTATION } & \\ \boldsymbol{A}_{i j} & \begin{array}{l}\text { position vector of point } i \text { in the frame of } \\ \text { reference of point } j\end{array} \\ b & \begin{array}{l}\text { contact half-width } \\ \text { damping constant }\end{array} \\ c & \text { constraint function } \\ C & \text { instantaneous cam diameter } \\ D & \text { modulus of elasticity } \\ E & \text { camshaft frequency } \\ f & \text { fundamental valve spring frequency } \\ f_{0} & \text { valve spring preload } \\ f_{\mathrm{p}} & \text { vector of generalized forces } \\ \boldsymbol{F}_{q} & \text { gravitational acceleration } \\ g & \text { modulus of rigidity } \\ G & =E \alpha \\ G^{*} & \text { lubricant film thickness } \\ h & \text { dimensionless lubricant film thickness } \\ h^{*} & \text { mass moment of inertia } \\ I & \text { geometrical acceleration } \\ j_{\phi} & \text { second area moment of inertia } \\ J & \text { valve spring rate } \\ k_{\mathrm{s}} & \end{array}$

The MS was received on 24 February 1999 and was accepted after revision for publication on 16 November 1999.

*Corresponding author: Department of Mechanical Engineering, University of Bradford, Bradford BD7 1DP, UK.

$\begin{array}{ll}K & \text { kinetic energy } \\ l & \text { camshaft length } \\ L_{\mathrm{c}} & \text { contact length } \\ L_{\mathrm{v}} & \text { valve length } \\ m & \text { mass } \\ n & \text { number of constraints } \\ N & \text { normal to the curve } \\ p & \text { Hertzian or EHL pressure } \\ p_{\mathrm{r}} & \text { cam contact profile } \\ P^{*} & =p / E \\ q, q^{*} & \text { reduced hydrodynamic pressure in the } \\ \{\boldsymbol{q}\} & \text { Reynolds equation } \\ R & \text { generalized coordinates } \\ & \text { instantaneous reduced radius of the } \\ R_{0} & \text { counterformal contact } \\ s & \text { base circle radius of cam } \\ t & \text { follower lift } \\ T & \text { time } \\ T_{q} & \text { tangent to curve } \\ u & \text { generalized torque } \\ U^{*} & \text { entraining velocity } \\ w_{\mathrm{s}}^{*} & =U \eta /(E R) \\ W & \text { squeeze-roll speed ratio } \\ W^{*} & \text { contact load } \\ x, y, z & =W /(E R L) \\ X, Y, Z & \text { local Cartesian frame of reference } \\ & \text { global Cartesian frame of reference } \\ & \end{array}$




$\begin{array}{ll}\alpha & \text { lubricant piezoviscosity index } \\ \beta & \text { cam event angle } \\ \delta & \text { contact deflection } \\ \eta & \text { lubricant viscosity [15] } \\ \lambda & \text { Lagrange multiplier } \\ v & \text { Poisson's ratio } \\ \rho & \text { lubricant density } \\ \psi, \theta, \phi & \text { Euler angles }\end{array}$

\section{INTRODUCTION}

The contact between cam and follower accounts for a significant proportion of the frictional losses in the internal combustion engines $[\mathbf{1}, \mathbf{2}]$. A progressive need has arisen for a higher output power-weight ratio in modern motor vehicles and in particular for racing cars. Valve train dynamic performance has thus become a critical factor. However, faster valve accelerations can induce certain undesired dynamic effects such as contact separation due to valve spring surge, referred to as jump and bounce in the valve seat contact. The inertial imbalances can be exacerbated by such effects and can render unacceptable levels of noise, vibration and harshness (NVH) [3, 4]. Jump in the cam-follower contact and bounce in the valve seat contact can induce premature component failure by fatigue and loss of lubrication (even in short transit times). The latter can lead to wear of contacting members. These problems are particularly exaggerated at high speeds, requiring a more detailed dynamic analysis of the entire assembly. On the other hand, at low speeds, such as in cold start-up conditions, lubricated contact conditions are adversely affected by the formation of a very low oil-film thickness $[\mathbf{5}, \mathbf{6}]$. Indeed under steady state conditions, theoretical analyses point to the loss of lubricant film in the vicinity of and immediately prior to the cam nose-follower contact $[7,8]$ under pure entraining motion. In fact, it is claimed, through theoretical investigations, that in the aforementioned regions the predominant regime of lubrication is due to boundary films. Experimental evidence reported by Hamilton [5] does not concur with these theoretically based suppositions. Until recently, the presence of a lubricant film measured in these regions could not be explained using the theory of elastohydrodynamic lubrication (EHL). Solutions obtained for transient EHL conditions point to a combined entraining and squeeze film action $[7,8]$. The critical role of squeeze film action in lubricant film retention is now established, particularly when lubricant film formation due to entraining action becomes insignificant $[9, \mathbf{1 0}]$. This can occur either at low speeds of entraining motion or as a result of inlet boundary reversal in the vicinity of the cam nose-flat follower contact.

Design of new valve trains is critically affected by a number of major factors, including the cam-follower contact condition, the valve spring surge and the inertial dynamics of the constrained assembly. Structural compliance also plays a significant role, such as the stiffness of the camshaft in the cycloidal cam-flat follower arrangement reported here.

The trend for future developments in internal combustion engines is to increase valve accelerations while minimizing NVH effects. This points to a reduction in the mass of the inertial members (i.e. using lighter cams and followers and their attachments), thereby reducing the valve spring rate. However, use of lighter materials can result in reduced fatigue strength of contacting members. This points to a combinatorial problem, requiring a compromise in design between the choice of various parameters. Furthermore, it calls for a holistic approach, incorporating both the NVH aspects of the valve train and cam-follower lubricated contact dynamics. This paper highlights a detailed methodology for such an integrated study.

\section{MULTI-BODY MODEL}

The valve train system is considered as a tribo-multibody dynamic model. It comprises the inertial components of the system, referred to as 'parts', the assembly constraints, sources of compliance such as the valve spring, contact compliance and elasticity of the camshaft and the lubricated conjunction between the cam and the flat follower. Two models are described in the paper, one with a rigid camshaft and the other incorporating camshaft elasticity.

\subsection{Inertial parts}

There are five parts in the model, including the ground or fixed datum to which the global Euler frame of reference is attached. It also includes valve train components such as the cam, the camshaft, the follower, the spring retainer, the valve/follower and two point masses that represent the distributed mass of the valve spring. The two point masses are enough to represent the clamped-clamped arrangement of the valve spring in order to examine the spring surge effect. The mass and inertial properties of these parts are provided in Table 1 . The camshaft in the elastic model is also represented by a series of point mass/inertial elements, restrained together by dynamic stiffness and damping matrices as non-linear threedimensional compliance influence coefficient matrices.

\subsection{Constraints}

Parts in the multi-body model are assembled together by holonomic and non-holonomic constraint functions to ensure their design functional performance. These constraints are applied at given geometric locations between 
Table 1 Inertial elements in the valve train model

\begin{tabular}{lcccr}
\hline Part name & Mass $(\mathrm{kg})$ & $I_{x x}\left(\mathrm{~kg} \mathrm{~mm}^{2}\right)$ & $I_{y y}\left(\mathrm{~kg} \mathrm{~mm}^{2}\right)$ & $I_{z z}\left(\mathrm{~kg} \mathrm{~mm}^{2}\right)$ \\
\hline Camshaft portion & $0.15-0.20$ & $55-70$ & $55-70$ & $170-200$ \\
Cam & $0.20-0.30$ & $73-90$ & $53-85$ & $98-135$ \\
Valve/follower & $0.20-0.25$ & $198-210$ & $30-45$ & $198-210$ \\
Spring mass (5) & $0.005-0.010$ & $0.0075-0.015$ & $0.0075-0.015$ & $0.0075-0.015$ \\
Spring mass (6) & $0.005-0.010$ & $0.0075-0.015$ & $0.0075-0.015$ & $0.0075-0.015$ \\
\hline
\end{tabular}

Table 2 Constraints in the valve train model

\begin{tabular}{llll}
\hline$I$ part name & $J$ part name & Constraint type & DOF removed \\
\hline Camshaft & Ground & Cylindrical & 4 \\
Cam & Valve/follower & Curve-curve & 2 \\
Valve/follower & Ground & Translational & 5 \\
Spring mass (5) & Ground & Translational & 5 \\
Spring mass (6) & Ground & Translational & 5 \\
\hline
\end{tabular}

parts. Table 2 lists the joints in the model. Each joint includes a number of constraints that are represented by scalar algebraic constraint functions. These functions yield non-linear algebraic equations.

Curve-curve adherence constraint functions are employed between the flat follower and the cam radial profile. These introduce two scalar algebraic functions that inhibit the separation of the two bodies. Therefore, a point on the cam surface remains in contact with the tappet at all times. Contact separation is only allowed through elastic deformation in the contact owing to the generation of elastohydrodynamic pressures. The valve spring surge influences the contact deformation and thus affects the EHL film. The EHL film is formed by the combined effect of entraining motion and squeeze film action. Contact misalignment occurs as a result of camshaft local flexion. The effect of tappet spin is not included.

\subsection{Sources of compliance}

The sources of compliance in a real valve train are manifold. These include the following:

(a) valve spring stiffness and damping,

(b) the contact compliance in the lubricated conjunction between the cam and follower,

(c) the contact compliance between the valve stem and the valve seat,

(d) tangential traction in the contact domain which is omitted in the current analysis.

The valve spring stiffness is considered as a two-degreeof-freedom compliance. In automotive valve trains, the valve spring coils are irregularly spaced, resulting in nonlinear characteristics. Such springs can be modelled by

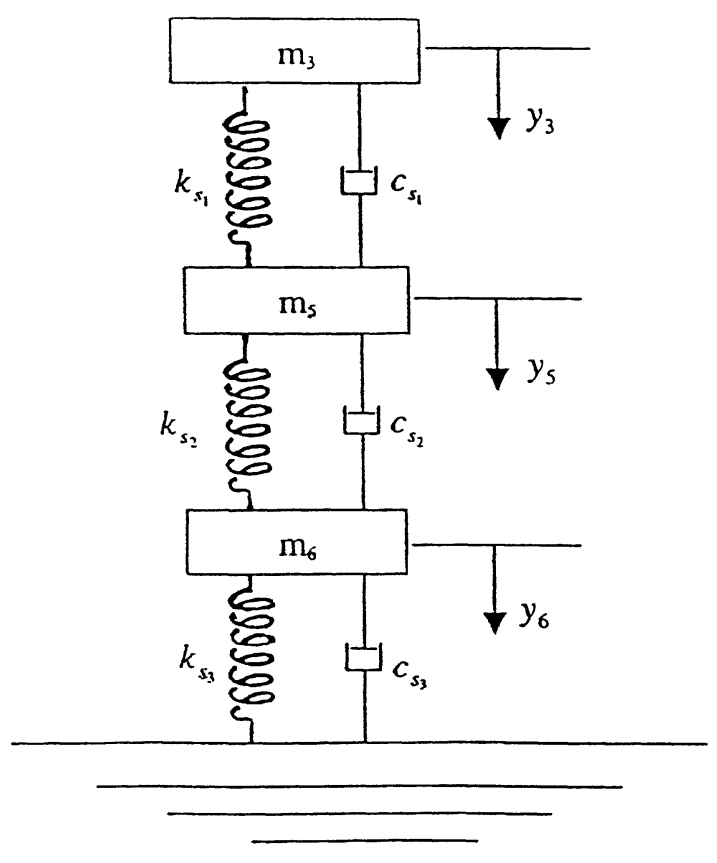

Fig. 1 Lumped mass model of the valve spring

lumped parameter formulation. The three stiffness components in the valve spring model, shown in Fig. 1, are obtained by making the following assumptions. Firstly, symmetry is assumed in the two-degree-offreedom valve spring model: $k_{\mathrm{s}_{1}}=k_{\mathrm{s}_{3}}$ and $c_{\mathrm{s}_{1}}=c_{\mathrm{s}_{3}}$. Secondly, it is assumed that the distributed system undergoes the same static deflection and responds at the same fundamental natural frequency. These assumptions yield the second natural frequency of the clampedclamped system to be twice the fundamental natural frequency of the spring assembly. Thus:

$$
\begin{aligned}
& m_{5}=m_{6}=\frac{2}{3}\left(\frac{k_{0}}{\pi f_{0}^{2}}\right) \\
& k_{\mathrm{s}_{2}}=4 k_{0} \\
& k_{\mathrm{s}_{1}}=k_{\mathrm{s}_{3}}=\frac{8}{3} k_{0}
\end{aligned}
$$

The values for this model are $k_{0}=35 \mathrm{kN} / \mathrm{m}$ and $f_{0}=$ $504.5 \mathrm{~Hz}$. 


\subsection{Cam-tappet concentrated contact}

The cam-flat follower contact at a particular cam angle can be regarded to be the same as the contact that a roller of the same radius as the cam instantaneous radius makes with an elastic half-space. A dry contact under this condition obeys the classical Hertzian theory for a roller indenting a semi-infinite elastic half-space. The Hertzian theory assumes that the surfaces of the roller and the plane are perfectly frictionless and hence the generated reaction forces are normal to the plane of contact. When the two bodies are elastic, the contact length is assumed to be slightly shorter than the roller length and the strains that are applied remain within the elastic limit. The contact width is necessarily small in comparison with the principal radii of curvature of the bodies, in this case the instantaneous cam radius.

Using the Hertzian theory, the deflections under the induced contact pressure at any point in the contact region can be obtained as [11]

$$
\begin{aligned}
\delta(x, y)= & \left(\frac{1-v_{1}^{2}}{\pi E_{1}}+\frac{1-v_{2}^{2}}{\pi E_{2}}\right) \\
& \times \int_{x_{1}} \int_{y_{1}} \frac{p(x, y)}{\sqrt{\left(x-x_{1}\right)^{2}+\left(y-y_{1}\right)^{2}}} \mathrm{~d} x_{1} \mathrm{~d} y_{1}
\end{aligned}
$$

It has been shown that an elliptical pressure distribution in the transverse direction for dry contacts approximates well with the Hertzian theory $[\mathbf{1 1}, \mathbf{1 2}]$. This, of course, is not the case for lubricated contacts under an EHL condition. The EHL pressure distribution conforms with the Hertzian pressure profile, except for the inlet trail and the exit secondary pressure peak. The conformance with the Hertzian conditions improves under starved contact conditions, this being a feature of cam-follower contact. Therefore, the contact deformation can be obtained from the Hertzian pressure distribution. This enables an analytical evaluation of central contact deflection. Such an expression can be included in the multi-body model and eliminates the need to solve the elasticity problem at each discrete time step during the transient contact dynamics of the system. The EHL of finite line contact is described by Rahnejat [9], who obtained an extrapolated oil-film thickness formula as a function of governing dimensionless EHL parameters. These parameters are described below. The extrapolated oil-film thickness formula in reference [9] includes the effect of squeeze film motion and is therefore used in the current analysis to estimate the oil-film thickness at each time step.

Assuming a lateral Hertzian elliptical pressure profile and that the pressure and footprint half-width at any section are proportional to their respective values at the contact centre $[\mathbf{1 1}, \mathbf{1 2}]$, then

$$
\frac{b_{1}}{p_{1}}=\frac{b_{0}}{p_{0}}=\frac{D}{4 E}
$$

The central contact half-width and the corresponding pressure can be obtained from the classical Hertzian theory as

$$
\begin{aligned}
& b_{\mathrm{o}}^{2}=\frac{2}{\pi}\left(\frac{1-v_{1}^{2}}{E_{1}}+\frac{1-v_{2}^{2}}{E_{2}}\right) \frac{W D}{L_{\mathrm{c}}} \\
& p_{\mathrm{o}}=\frac{2 W}{\pi b_{\mathrm{o}} L_{\mathrm{c}}}
\end{aligned}
$$

The lateral elliptical pressure profile in any cross-section of the overall pressure distribution is given by

$$
p\left(x_{1}, y_{1}\right)=p_{1}\left[1-\left(\frac{x_{1}}{b_{1}}\right)^{2}\right]^{1 / 2}
$$

Substituting from equation (8) in equation (5), and integrating over the contact domain, the deflection at any point $x, y$ can be obtained. This procedure can be carried out for all points within the contact domain. For the central contact point (i.e. $x=y=0$ )

$$
\delta(0,0)=b_{0} p_{0}\left(\frac{1-v_{1}^{2}}{E_{1}}+\frac{1-v_{2}^{2}}{E_{2}}\right)\left(\ln \frac{4 b}{b_{0}}+0.5\right)
$$

The above elastostatic analysis assumes an instantaneous axial uniform pressure distribution. This assumption yields a rectangular footprint which deviates from reality, where the footprint has been shown to approximate to a 'dog-bone' shape [11-13]. To obtain the film thickness and the correct pressure distribution, a solution to the finite line EHL problem must be obtained.

\section{FORMULATION OF THE ELASTOHYDRODYNAMIC CONJUNCTION}

The lubricated contact pressure distribution occurs axially along the depth of the cam, and laterally along the direction of entraining motion, with the contact halfwidths in all cross-sections being much smaller than the contact length. This gives rise to a line contact condition of finite length. Therefore, a finite line EHL solution is sought. A simultaneous isothermal solution for the Reynolds hydrodynamic equation and the elastic film shape should be undertaken. Solutions for the finite line contact EHL problem have been attempted to a much lesser extent than those for elliptical point contact conditions. The main solutions have been by Mostofi 
[14], Mostofi and Gohar [10] and Rahnejat [9]. The work in reference [9] includes the effect of squeeze film action. Another solution has been reported by Dowson et al. [7] for the case of a cam-follower contact.

A simultaneous quasi-static solution of the EHL problem with the multi-body elastodynamic model renders an unacceptable computation time. The solution for the latter is carried out in a large number of time intervals, typically in the region of 500 steps for each cam revolution. The time requirement for a solution of the EHL problem is typically in the region of 5-7 h per time step. Therefore, a simultaneous solution is impractical. However, the effect of the lubricated contact dynamics in the multi-body analysis is essential. An appropriate approach is to obtain an extrapolated equation to describe the non-linear characteristics of the EHL conjunction under transient contact dynamic conditions. The solution of the EHL problem under combined entraining and squeeze film motion has been shown to yield equations that can be used in the dynamic analysis of bearings [16] and gears [17]. The same approach is undertaken here for the case of valve train multi-body dynamics.

Such equations have been obtained by Rahnejat [9]. For the central oil-film thickness

$$
h_{0}^{*}=1.67 W^{* 0.059} U^{* 0.541} G^{* 0.421} \mathrm{e}^{-96.775 w_{\mathrm{s}}^{*}}
$$

The extrapolated oil-film equation clearly has a number of limitations. The range of its applicability with regard to the governing parameters $W^{*}, G^{*}, w_{\mathrm{s}}^{*}$ and $U^{*}$ is given in Table 3. The equation was obtained by Rahnejat [9] by regression of numerical results obtained by quasi-static analysis of combined entraining and squeeze film motion. It has been shown by Wijnant and Venner [18] that, with such solutions, an 'average steady' squeeze velocity is assumed, rather than an instantaneous value that prevails under transient conditions. The authors have shown that, when the speed of entraining motion dominates (i.e. with low values of $w_{\mathrm{s}}^{*}$ ), the quasi-static solution approximates the transient conditions closely. However, the conformity to the real transient conditions deteriorates when significant instantaneous squeeze film motion takes place or the speed of entraining motion diminishes, such as in the regions just prior to and after the cam nose contact.

Table 3 Range of dimensionless parameters used in regression of the oil-film equation (10) [9]

\begin{tabular}{ll}
\hline Grouping & Range \\
\hline$G^{*}$ & $5700-9650$ \\
$w_{\mathrm{s}}{ }^{*}$ & $-0.005-0$ \\
$W^{*}$ & $0.34 \times 10^{-6}-0.56 \times 10^{-5}$ \\
$U^{*}$ & $0.63 \times 10^{-11}-3.3 \times 10^{-11}$ \\
\hline
\end{tabular}

The solution using the extrapolated equation also assumes isothermal Newtonian conditions, which is not representative of the practical situation, where high tractive forces and rising contact temperature call for transient thermoelastohydrodynamic solutions for nonNewtonian behaviour. Finally, the solutions by Rahnejat [9] assume that all the points in the contact conjunction have the same squeeze velocity. This can lead to an incorrect history of deformation and lubricant film thickness.

\section{MULTI-BODY MODEL FORMULATION}

There are five parts in the multi-body model (see Table 1 ), the motion of each of which can be described in terms of generalized coordinates, $\{\boldsymbol{q}\}$, by Lagrange's equation for constrained systems:

$$
\frac{\mathrm{d}}{\mathrm{d} t}\left(\frac{\partial K}{\partial \dot{q}}\right)-\frac{\partial K}{\partial q}-\boldsymbol{F}_{q}+\sum_{k=1}^{n} \lambda_{k} \frac{\partial C_{k}}{\partial q}=0
$$

The generalized coordinates are given by $\{\boldsymbol{q}\}=\{x, y, z$, $\psi, \theta, \varphi\}^{\mathrm{T}}$, where the rotational components are given in the Euler 3-1-3 frame of reference.

The reaction forces in the multi-body system are given by the summation term in equation (11) along each of the generalized coordinates. These are introduced by nonlinear algebraic scalar functions, $C_{k}$. Therefore, the assembly of parts can be represented mathematically in a manner that conforms to the required dynamic functions of the system.

Under dynamic conditions, equation (11) provides six equations of motion per part in the valve train system. Each equation of motion is reduced to a pair of first-order equations.

\subsection{Constraint functions}

Note that the motions in the valve train model are prescribed by the camshaft rotation and the valve translation, both of which are governed by the combustion process. The coupled action of cam rotation and valve timing is determined by the cam lift profile.

The holonomic constraint functions are formulated for each joint type as:

(a) cylindrical joint:

$$
\begin{aligned}
& z_{i} x_{j}=0, \quad z_{i} y_{j}=0, \quad \boldsymbol{A}_{i j} x_{j}=0, \\
& \boldsymbol{A}_{i j} y_{j}=0
\end{aligned}
$$

where $\boldsymbol{A}_{i j}$ is the position vector of point $i$ in the local part frame of reference of point $j$. 
(b) translational joint:

$$
\begin{aligned}
& y_{i} x_{j}=0, \quad y_{i} z_{j}=0, \quad x_{i} z_{j}=0, \quad \boldsymbol{A}_{i j} x_{j}=0, \\
& \boldsymbol{A}_{i j} z_{j}=0
\end{aligned}
$$

(c) curve-curve:

$$
T_{i} N_{j}=0, \quad T_{j} N_{i}=0
$$

Camshaft rotation is given by the non-holonomic constraint function, describing its prespecified motion as

$$
\psi_{i}=2 \pi f t
$$

Now the Euler transformation matrix is employed in order to transform the above constraint functions into algebraic equations in terms of the generalized coordinates $\{x, y, z, \psi, \theta, \varphi\}^{\mathrm{T}}$. The transformation matrix is given in Appendix 1.

Transformation for the above constraint functions results in the following algebraic equations (the numerical subscripts denote the part numbers in the model, referred to in Table 1):

(a) for the cylindrical joint between the camshaft and the ground:

$$
\begin{aligned}
& C_{1}=\boldsymbol{A}_{14} x_{4}=x_{1}-l\left(\mathrm{C} \psi_{1} \mathrm{C} \phi_{1}-\mathrm{S} \psi_{1} \mathrm{C} \theta_{1} \mathrm{~S} \phi_{1}\right)=0 \\
& C_{2}=\boldsymbol{A}_{14} y_{4}=y_{1}+l\left(\mathrm{~S} \psi_{1} \mathrm{~S} \phi_{1}-\mathrm{C} \psi_{1} \mathrm{C} \theta_{1} \mathrm{C} \phi_{1}\right)=0 \\
& C_{3}=z_{1} x_{4}=\mathrm{S} \theta_{1} \mathrm{~S} \phi_{1}=0 \\
& C_{4}=z_{1} y_{4}=\mathrm{S} \theta_{1} \mathrm{C} \phi_{1}=0
\end{aligned}
$$

where $\mathrm{C} \equiv \cos , \mathrm{S} \equiv \sin$;

(b) for the translational joint between the valve and the ground:

$$
\begin{aligned}
& C_{5}=\boldsymbol{A}_{34} x_{4} \\
& \quad=x_{3}-L_{\mathrm{v}}\left(\mathrm{C} \psi_{3} \mathrm{C} \phi_{3}-\mathrm{S} \psi_{3} \mathrm{C} \theta_{3} \mathrm{~S} \phi_{3}\right)=0 \\
& C_{6}=\boldsymbol{A}_{34} z_{4}=z_{3}-L_{\mathrm{v}}\left(\mathrm{C} \theta_{3}\right)=0 \\
& C_{7}=y_{3} x_{4}=\mathrm{S} \psi_{3} \mathrm{C} \phi_{3}+\mathrm{C} \psi_{3} \mathrm{C} \theta_{3} \mathrm{~S} \phi_{3}=0 \\
& C_{8}=y_{3} z_{4}=-\mathrm{C} \psi_{3} \mathrm{~S} \theta_{3}=0 \\
& C_{9}=x_{3} z_{4}=\mathrm{S} \psi_{3} \mathrm{~S} \theta_{3}=0
\end{aligned}
$$

(c) for the curve-curve constraint between the cam and the follower:

$$
N_{3}=y_{3}
$$

$$
T_{2}=\frac{\partial y_{2}}{\partial \psi_{2}}
$$

$$
C_{10}=T_{2} N_{3}=\left(\frac{\partial y_{2}}{\partial \psi_{2}}\right) y_{3}=0
$$

$$
N_{2}=y_{2}
$$

$$
T_{3}=x_{3}
$$

$$
C_{11}=T_{3} N_{2}=x_{3} y_{2}=0
$$

where

$$
y_{2}=s\left\{\frac{\psi_{2}}{\beta}-\left[\frac{1}{2 \pi} \sin \left(\frac{2 \pi \psi_{2}}{\beta}\right)\right]\right\}
$$

(d) for camshaft rotation:

$$
C_{12}=\psi_{1}=2 \pi f t=0
$$

\subsection{Camshaft flexibility}

In the elastic model the camshaft is modelled by two inertial point masses, connected by a three-dimensional elastic field, represented by a stiffness and a damping matrix. The field element matrices provide the forces/moments at a marker $i$ owing to a relative displacement with respect to a marker $j$. The threedimensional field element requires an initial alignment of the two markers, having a co-directed $x$ axis. Thus:

$$
\left[\begin{array}{c}
F_{x} \\
F_{y} \\
F_{z} \\
T_{x} \\
T_{y} \\
T_{z}
\end{array}\right]
$$




$$
\begin{gathered}
=\left[\begin{array}{cccccc}
\frac{E A}{l} & 0 & 0 & 0 & 0 & 0 \\
0 & \frac{12 E J_{z z}}{l^{3}} & 0 & 0 & 0 & \frac{-6 E J_{z z}}{l^{2}} \\
0 & 0 & \frac{12 E J_{y y}}{l^{3}} & 0 & \frac{6 E J_{y y}}{l^{2}} & 0 \\
0 & 0 & 0 & \frac{G J_{x x}}{l} & 0 & 0 \\
0 & 0 & \frac{6 E J_{y y}}{l^{2}} & 0 & \frac{4 E J_{y y}}{l} & 0 \\
0 & \frac{-6 E J_{z z}}{l^{2}} & 0 & 0 & 0 & \frac{4 E J_{z z}}{l}
\end{array}\right] \\
\times\left[\begin{array}{c}
x_{4}-l \\
y_{4} \\
z_{4} \\
\theta_{4} \\
\phi_{4} \\
\psi_{4}
\end{array}\right]-[\mathbf{c}]\left[\begin{array}{c}
\dot{x}_{4} \\
\dot{y}_{4} \\
\dot{z}_{4} \\
\dot{\theta}_{4} \\
\dot{\phi}_{4} \\
\dot{\psi}_{4}
\end{array}\right]
\end{gathered}
$$

where $[\mathbf{c}]$ is the structural damping matrix, the elements of which are taken to be 2 per cent of their respective values within the stiffness matrix.

\subsection{Formulation of the Jacobian matrix}

The set of differential-algebraic equations described above is represented in matrix form as

$$
[\mathbf{J}]\{\boldsymbol{q}, \boldsymbol{\lambda}\}^{\mathrm{T}}=\left\{\boldsymbol{F}_{q}\right\}
$$

where $[\mathbf{J}]$ is the Jacobian matrix, $\{\boldsymbol{q}, \boldsymbol{\lambda}\}^{\mathrm{T}}$ is the required solution vector in all small time steps, $\mathrm{d} t$, and $\left\{\boldsymbol{F}_{q}\right\}$ is the vector of applied forces. The Jacobian matrix is of the following form:

$$
[\mathbf{J}]=\left[\begin{array}{cc}
{\left[\frac{s}{\mathrm{~d} t} \frac{\partial K}{\partial \dot{q}}+\frac{\partial K}{\partial q}\right]} & {\left[\frac{\partial C}{\partial \lambda}\right]} \\
{\left[\frac{\partial C}{\partial q}\right]} & {[0]} \\
{\left[\frac{\partial F_{q}}{\partial q}\right]} & {\left[\frac{\partial F_{q}}{\partial \dot{q}}\right]}
\end{array}\right]
$$

The submatrix at the top left-hand corner of the Jacobian matrix is the inertial matrix. This submatrix is a $15 \times 15$ matrix for each part within the multi-body model. An example for this submatrix for a typical part (in this case the cam) is shown in Appendix 2.

The functions related to the applied forces and the influence coefficients for the system compliance func- tions [given by the stiffness and damping matrices in equation (33)] are represented by the derivative matrices in the last row of the Jacobian matrix. These include the field matrices for the camshaft and the valve spring. The submatrix at the top right-hand corner of the Jacobian matrix provides the Lagrange multiplier coefficients, while the first submatrix in the middle row gives the constraint-related functions. This submatrix for the multibody valve train model is given in Appendix 3 .

The inertial submatrix contains the Jacobian terms for the six equations, each of which is reduced to a pair of first-order differential equations. Additionally, the equations of motion for the rotational degrees of freedom are represented in terms of rate of change in momenta, thus requiring the inclusion of the three momentum equations in the Euler frame of reference. Therefore, 15 equations are used to describe the motion of each part in the multibody model. There are four parts (excluding the ground) in the model, yielding a total of 60 differential equations.

The vector of unknowns: $\{\boldsymbol{q}, \boldsymbol{\lambda}\}^{\mathrm{T}}=\left\{\boldsymbol{\zeta}_{i}, \boldsymbol{q}_{i}, \boldsymbol{\lambda}_{k}\right\}^{\mathrm{T}}$ where $i=1-5, \quad k=1-21$ and $\left\{\boldsymbol{\zeta}_{i}\right\}=\left\{\dot{\boldsymbol{q}}_{i}\right\}$. The solution procedure is fully described in reference [4].

\subsection{Lubricated contact conjunction}

The cam-follower contact is treated as an elastohydrodynamic finite line contact conjunction. The instantaneous integrated lubricant pressure distribution is the vertical component of the curve-curve constraint acting upon the follower and is given by

$$
W=\frac{s}{\beta}\left[1-\mathrm{C}\left(\frac{2 \pi \psi_{1}}{\beta}\right)\right] \lambda_{6}
$$

where $W$ is a function of the oil-film thickness, given by the extrapolated oil-film thickness equation (10), and C denotes the cosine function. Therefore, the lubricant film thickness $h=h^{*} R$ can be obtained from expression (10) by replacing for the dimensionless groups [with the load obtained from equation (35)].

When cam lift occurs, the cam-follower contact is subjected to a combined entraining and squeeze film motion. The lubricant film thickness and the corresponding squeeze film velocity are obtained at each time step as follows:

$$
\frac{\partial h_{n}}{\partial t}=\frac{h_{n-1}-h_{n}}{\Delta t}
$$

where

$$
h_{n}=R h_{0}^{*}
$$


The initial conditions for the first time step are

$$
h_{n-1}=h_{r}=R h_{0}^{*} \mid \frac{\partial h_{n-1}}{\partial t}=0 \quad \text { and } \quad h_{n}=1.05 h_{r}
$$

Equation (38) is used to determine the initial squeeze velocity, when the film thickness is nominally increased by 5 per cent. This condition merely provides a first value for the squeeze velocity.

\subsection{Dynamics of valve spring surge}

In the valve spring surge model, the equations of motion for the valve and the two lumped masses representing the valve spring are given by [see Fig. 1 and equations (1) to (3)]:

$$
\begin{aligned}
& m_{3} \dot{v}_{3}=k_{\mathrm{s}_{1}}\left(y_{3}-y_{5}\right)+c\left(\dot{y}_{3}-\dot{y}_{5}\right)-\left(W+f_{\mathrm{p}}\right) \\
& v_{3}=\dot{y}_{3} \\
& m_{5} \dot{v}_{5}=k_{\mathrm{s}_{2}}\left(y_{5}-y_{6}\right)+c\left(\dot{y}_{5}-\dot{y}_{6}\right)-k_{\mathrm{s}_{1}}\left(y_{3}-y_{5}\right) \\
& -c\left(\dot{y}_{3}-\dot{y}_{5}\right) \\
& v_{5}=\dot{y}_{5} \\
& m_{6} \dot{v}_{6}=k_{\mathrm{s}_{3}} y_{6}+c\left(\dot{y}_{6}\right)-k_{\mathrm{s}_{2}}\left(y_{5}-y_{6}\right)-c\left(\dot{y}_{5}-\dot{y}_{6}\right) \\
& v_{6}=\dot{y}_{6}
\end{aligned}
$$

\subsection{Kinematic analysis}

When the camshaft is assumed to be rigid and the spring surge effect is ignored, a kinematic model results. This simple model has two parts, the cam and the flat follower, the former constrained to the ground with a cylindrical joint with a predefined motion and having a curve-curve adherence constraint to the flat follower. The latter has a translational, single-degree-of-freedom specified motion to the ground. Therefore, the main interest in this case is in combined forced kinematic and lubricated contact dynamics of the valve train system. With the kinematic mechanism (as is the case with valve train systems with an assumed rigid camshaft), the inertial terms in the Lagrange equation are ignored, yielding a reduced Jacobian matrix that yields equation (41). This equation is then solved simultaneously with the 12 constraint functions for the required solution vector, comprising the state variables $q$ and the Lagrange multipliers $\lambda$ :

$$
\begin{aligned}
& {\left[\frac{\partial C}{\partial q}\right]\{\boldsymbol{\lambda}\}=-\left\{\boldsymbol{F}_{q}\right\}} \\
& C(q)=0
\end{aligned}
$$

This approach forms the basis of most available solutions incorporating lubricated contact dynamics $[\mathbf{7}, \mathbf{8}, \mathbf{1 9}]$. A comprehensive multi-body treatment of this problem is highlighted in reference [19].

\section{RESULTS AND DISCUSSION}

The main task in the design of a cam-follower friction pair is to ensure coherent lubrication by providing a sufficient oil-film thickness guarding against wear, while ensuring contact loads that do not exceed the fatigue strength limits. The estimation of the contact load is therefore very important in the design process. The maintenance of a high contact force is beneficial for a number of reasons. Firstly, the conditions that yield low loads can result in separation phenomena such as jump and bounce in the mechanism and contribute to noise and vibration. Secondly, low contact loads render reduced Hertzian pressures that can result in poor lubrication owing to diminution of elastohydrodynamic conditions. This finding is now generally accepted and has been corroborated by both experimental and theoretical investigations [5, 7, 20]. Quasi-static EHL solutions have indicated higher lubricant film thickness at higher Hertzian stresses than those generated by other prevalent regimes of lubrication at low contact loads $[\mathbf{7 , 8 , 2 0}]$. The rather complex relationship between dynamic contact loads and lubrication can only be studied in an integrated solution of valve train inertial and lubricated contact dynamics.

Inertial dynamic effects can be neglected at low valve translational speeds. A combined kinematic analysis of the mechanism with lubricated contact dynamics is then justified, as in the works reported in references $[7,8,19,20]$. However, at progressively increasing engine speeds, the spring surge effect becomes significant as shown by Kim et al. [21], and thus a full non-linear dynamic analysis becomes necessary. At higher speeds, larger dynamic forces occur, yielding higher contact forces that can be quite beneficial as highlighted above. However, at high speeds the inertial imbalance also increases, which can exacerbate the separation effects and induce noise and vibration, as well as wear and fatigue with jump and bounce in the mechanism, during which the retention of a coherent lubricant film becomes difficult.

In this paper a cycloidal cam profile, typical of a midheight camshaft and a flat follower arrangement, has been 


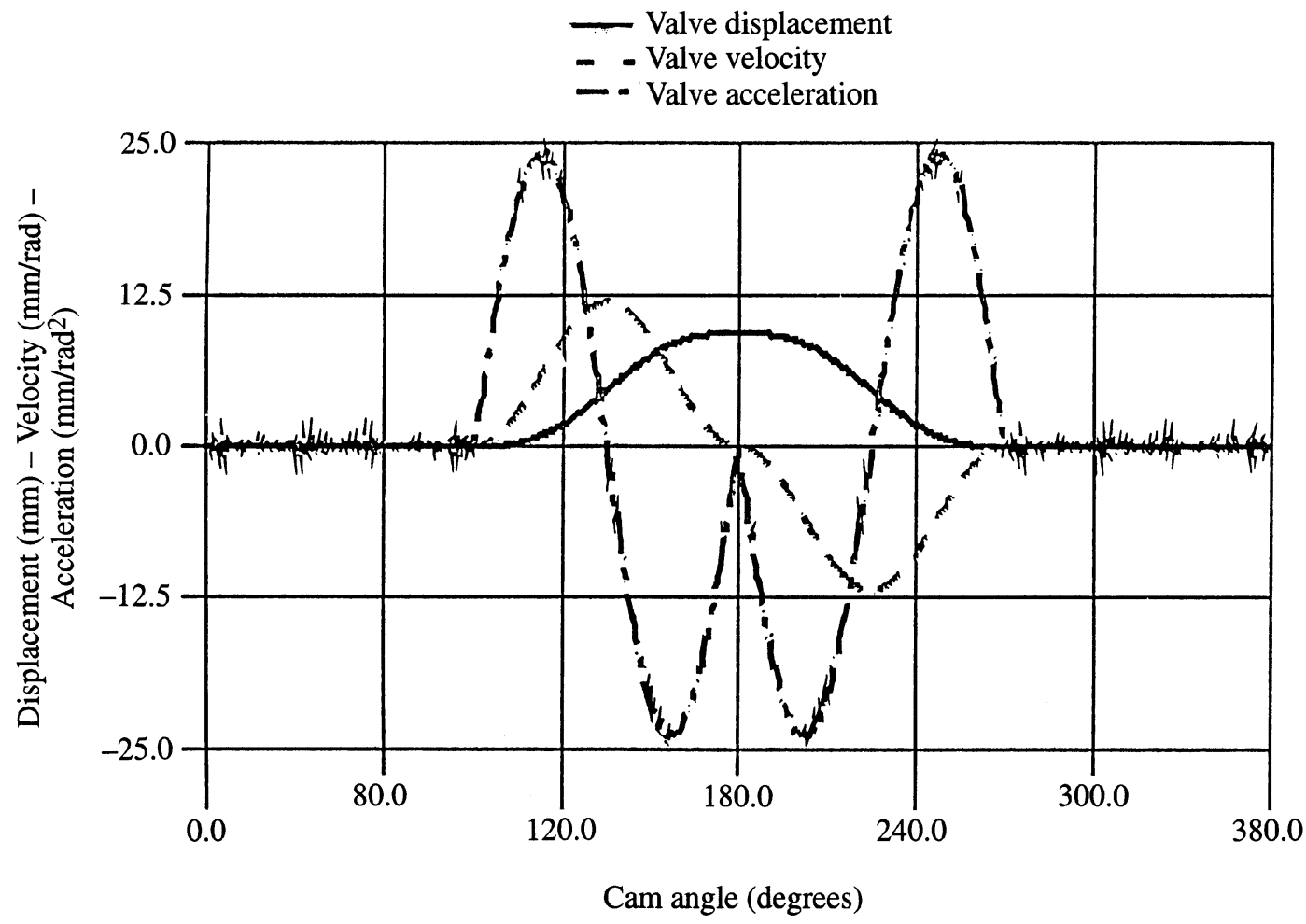

Fig. 2 Lift, velocity and acceleration characteristics of the cycloidal cam

employed. The cycloidal cam in such an arrangement can have a rather broadened flat nose in order to follow the required constant lift profile as shown in Fig. 2. The cycloidal curve is often used as a basis for designing cams, especially for high-speed applications [22]. It yields low noise, vibration and wear characteristics. It guards against sudden changes in valve train accelerations. In fact, for a determined rise time, the acceleration is somewhat higher than that for many other types of cam. These rather high accelerations ensure short-lived lubricant film diminution when zero entraining contact velocities are encountered. However, high values of acceleration and decelerations with cycloidal cams can result in high inertial forces and must be kept under control with correspondingly stiff valve springs. Therefore, valve train design problems are somewhat accentuated when cycloidal cams are employed. Precisely because of this, such a cam profile is employed in this study to illustrate the cam-follower design problems.

The kinematic relations for a flat follower are relatively simple. This allows for the differentiation of the valve lift over the cam angle, which yields the velocity and the acceleration profiles (also shown in Fig. 2). Note that for an arrangement of a cycloidal cam and a flat follower the follower acceleration has a sharp spike at the contact with the cam nose. This is because, with the cycloidal curve, the follower acceleration is symmetrical about the cam half-cycle. The advantage of this is that the acceleration variation is continuous [22]. The disadvantage of this is seen in lubrication conditions within the vicinity of and prior to the cam nose contact as the contact entraining velocity diminishes (see Fig. 3), pertaining to a loss of lubricant film thickness under steady state conditions. This disadvantage is alleviated by the fast contact transit time at high speeds (as previously discussed). Therefore, at low speeds of revolution the lubrication performance of this type of cam can be poor in the vicinity of the cam nose, based upon the theory of elastohydrodynamic lubrication. In fact, for a cycloidal cam of the type under investigation here, a zero lubricant film thickness under pure entraining motion is predicted (since the entraining velocity becomes zero at positions of $\pm 12^{\circ}$ and $\pm 36^{\circ}$ to the cam nose). This problem exists at two locations in automotive polynomial cams. However, experimental investigations of cam-follower contact by Hamilton [5], Dowson et al. [7] and Williamson et al. [23] have shown that a lubricant film appears to exist throughout the cam cycle. The EHL contribution in these positions is mainly due to the squeeze film effect, as well as to microfilms trapped in-between surface undulations. Furthermore, evidence of electrically insulating reaction films being formed on the contiguous surfaces in contact has been obtained $[\mathbf{1}, \mathbf{2 3}]$.

Transient EHL analysis has been carried out, for example by Dowson et al. [7], to show the significance of squeeze film action in cam-follower contacts, particularly in the regions with low speeds of entraining motion. Empirical formulae for lubricant film thickness for EHD line contact conditions have been obtained by various researchers $[9,10]$. These formulae correlate with the 


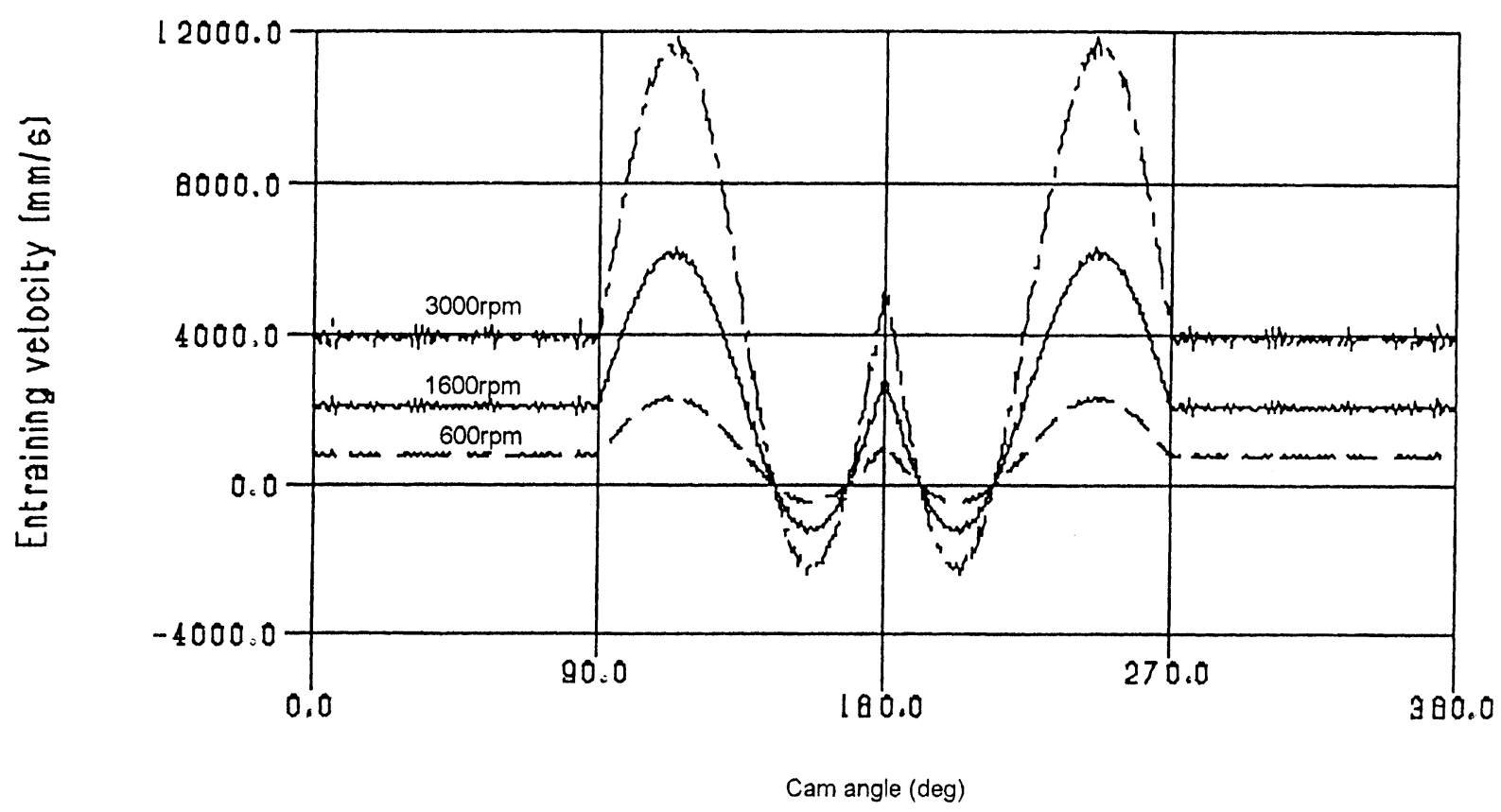

Fig. 3 Entraining velocity at different engine speeds

experimentally measured film reported by others $[\mathbf{5}, \mathbf{2 0}]$, except for regions where the speed of entraining motion is zero or subject to fast changes, indicating inlet boundary reversals.

In a study reported by Kushwaha et al. $[\mathbf{1 9}, \mathbf{2 4}]$, a finite line EHD contact under combined entraining and squeeze film motions is considered. A plot of lubricant film thickness against the cam angle was obtained for the case of the kinematic motion of the valve train with a lubricated contact under EHL condition. This is shown in Fig. 4 for a complete cam cycle. The cam nose location is designated to be at $180^{\circ}$, with the flank and nose actions occurring from $90^{\circ}$ to $270^{\circ}$. It should be noted that the entraining velocity crosses the zero value at four locations (as described above), corresponding to the instances of minimum film thickness shown in the figure. In this cycloidal cam, zero entraining velocities occur at $\pm 12^{\circ}$ as well as at $\pm 36^{\circ}$ to the cam nose location. The minimum lubricant film thickness is in the region of $0.04 \mu \mathrm{m}$. This is a very small film thickness that is rapidly replenished in a short interval of time. The transit time between the occurrence of the first and the last (i.e. the fourth) minima at the engine idling speed of $1000 \mathrm{r} / \mathrm{min}$ is in fact $1 \mathrm{~ms}$. Nevertheless, the major contribution to fluid

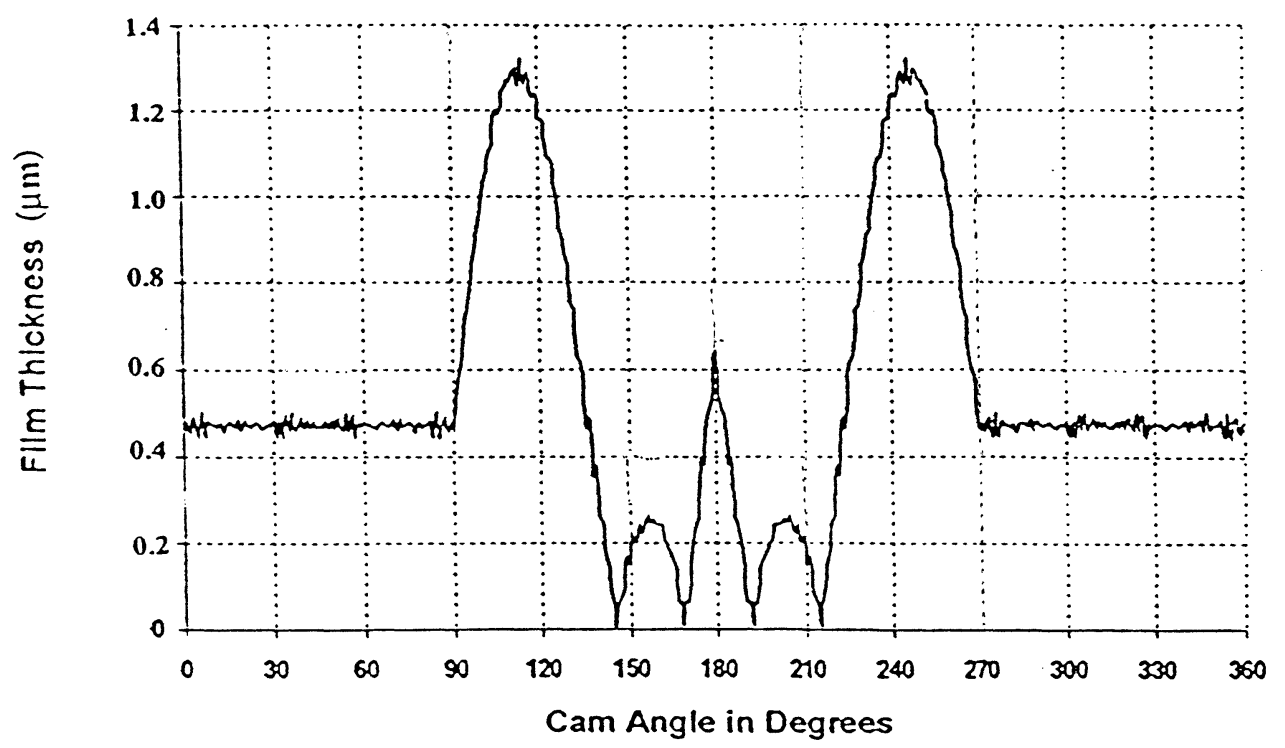

Fig. 4 Lubricant film thickness at the point of contact 


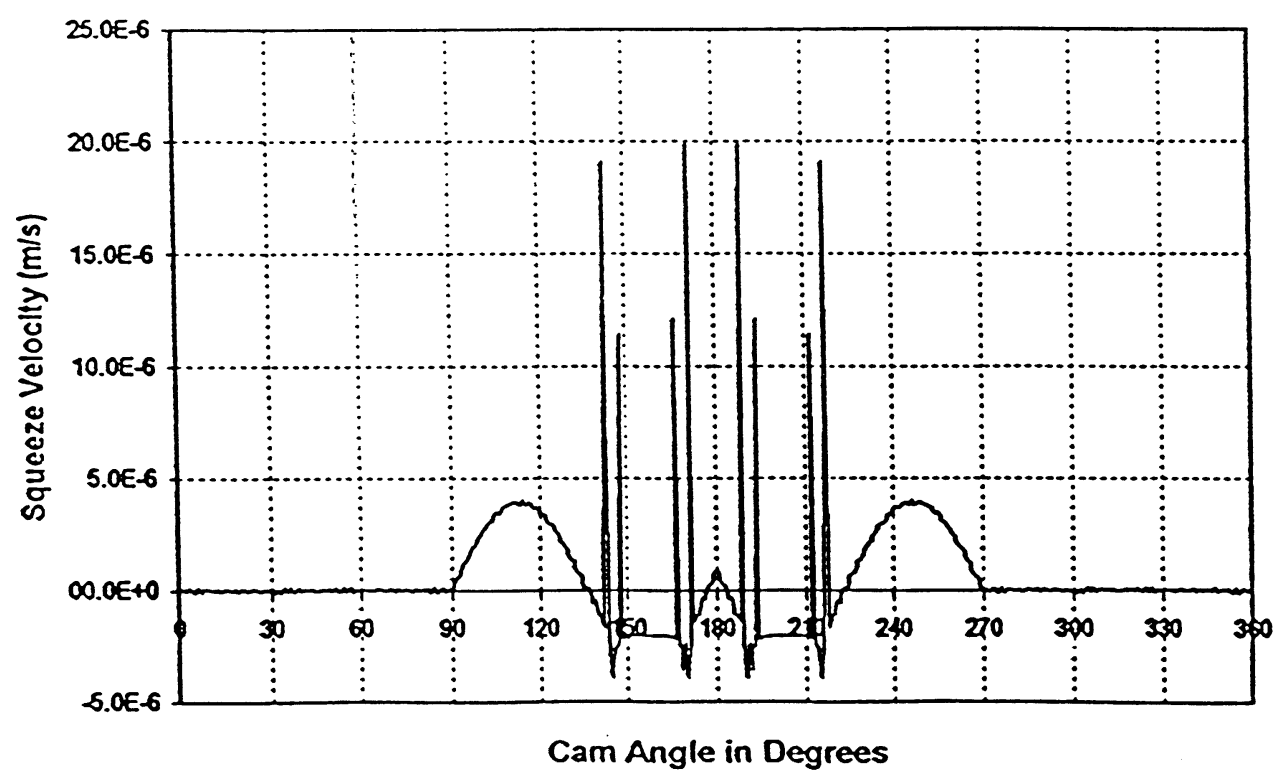

Fig. 5 Squeeze velocity at the point of contact

film formation between cam angles of $+36^{\circ}$ and $-36^{\circ}$ is by squeeze film lubrication. The contribution by entraining motion is minimal (in fact, non-existent at the four minima). This is illustrated in Fig. 5, showing the large squeeze velocity values that result in the vicinity of the lubricant film minima (see also Fig. 4). The positive values for the squeeze velocity indicate a separation effect in the contacting region, while the negative values indicate the subsequent mutual approach of mating members. The lubricant film at the nose is much larger because the speed of entraining motion there is in excess of $4 \mathrm{~m} / \mathrm{s}$, giving a film thickness of just below $1 \mu \mathrm{m}$. The lubricant film thickness is much larger in other regions, but never in excess of $1.3 \mu \mathrm{m}$ for this analysis. The conditions in this analysis are quite similar to those reported by Dowson et al. [7], except that in their case a fourth-order polynomial cam was employed.

The work reported in reference [19] is extended here to take into account the spring surge effect. The valve spring is modelled as a lumped mass system, as described above. Larger contact dynamic loads occur at higher engine speeds (see Fig. 6). This is due to the increased valve train inertial imbalance. The surge effect with increasing dynamic loads contributes to noise and fluctuations in the contact load, particularly in parts of the cam cycle with low contact forces. This is evident from the load perturbations superimposed upon the cyclic contact load profile at the camshaft speed of $3000 \mathrm{r} / \mathrm{min}$ in Fig. 6. In fact, this problem is usually more pronounced with polynomial automotive cams (see reference [7]). The increased contact loads facilitate better lubrication. On the flanks and on the broadened face of the cam nose in cycloidal cams, owing to the large radius of contact and with the increased speed of entraining motion, the conditions are particularly favourable, as shown in Fig. 7. In the regions with no entraining motion the load carried by the lubricant film is contributed by the squeeze film effect. In these regions the contact load remains almost unchanged (crossover points in Fig. 6) and the film thickness marginally increases with a small change in the squeeze film velocity. In practice, a more pronounced change would be anticipated owing to the valve jump effect, resulting in loss of contact through separation and a subsequent approach of the bodies in contact. In the current model, separation and approach are only permitted through contact deformation as indicated by equation (4).

The last issue in this analysis is related to camshaft elasticity. Camshaft wind-up and wind-down prior to and after the cam nose-follower contact occur with its insufficient stiffness. As the camshaft undergoes threedimensional torsional deflection oscillations, the floating point of contact between the cam and the follower is subjected to a superimposed oscillatory motion. The tangential deflection of the shaft perpendicular to the direction of valve life introduces a fictitious angular velocity [25]. The angular motion of the cam becomes distorted. This results in sharp oscillations superimposed upon the steady contact load, as can be seen in the results for the nominal camshaft speed of $600 \mathrm{r} / \mathrm{min}$ in Fig. 8. Note the increasing oscillatory amplitude prior to the cam nose contact (wind-up) and after it (wind-down). The reduced loads indicate jump, while the increased values correspond to bounce in the mechanism. If the contact between the cam and the follower is maintained at all times (an assumption imposed by the curve-curve constraint in this analysis), the follower speed of entraining motion is increased considerably by the contribution due to the geometrical acceleration, given 


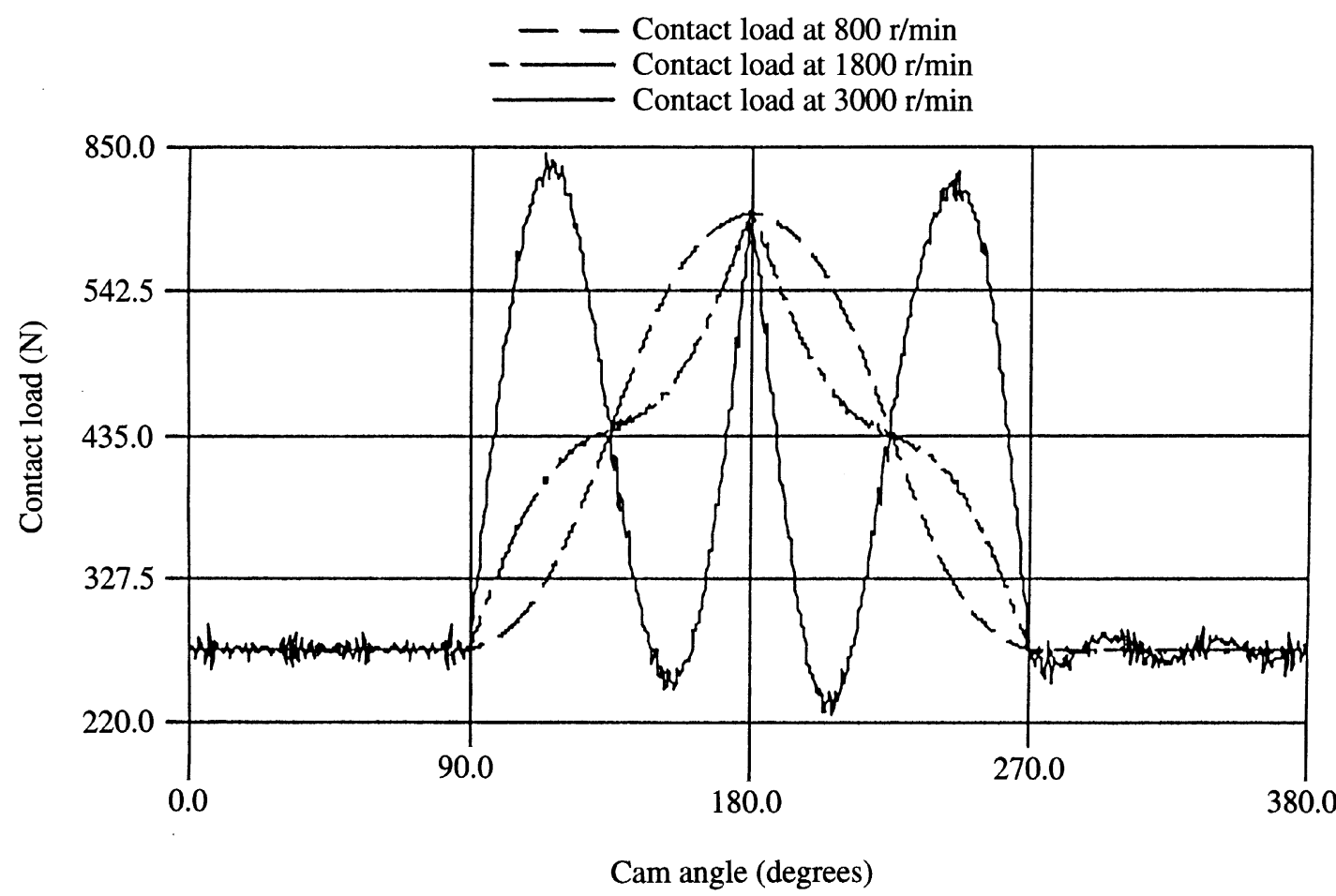

Fig. 6 Contact load variation at different speeds

by $j_{\phi}=\left(1 / \omega^{2}\right)\left(\mathrm{d}^{2} s / \mathrm{d} t^{2}\right)$ where $\omega=\bar{\omega}-\dot{r} / R$ and $u=$ $\frac{1}{2}\left(R_{0}+s+2 j_{\phi}\right)$. The speed of entraining motion can then be affected significantly, as indicated by the above relations, and the lubricant film thickness can increase or decrease accordingly. However, the current EHL analysis does not take into account the resulting misaligned contact of the cam and follower. An analysis of this for inclusion in the multi-body model will form the future direction of this research. Misaligned contact of rollers against an elastic half-space under dry elastostatic conditions has been reported by Johns and Gohar [11] and Rahnejat and Gohar [13].

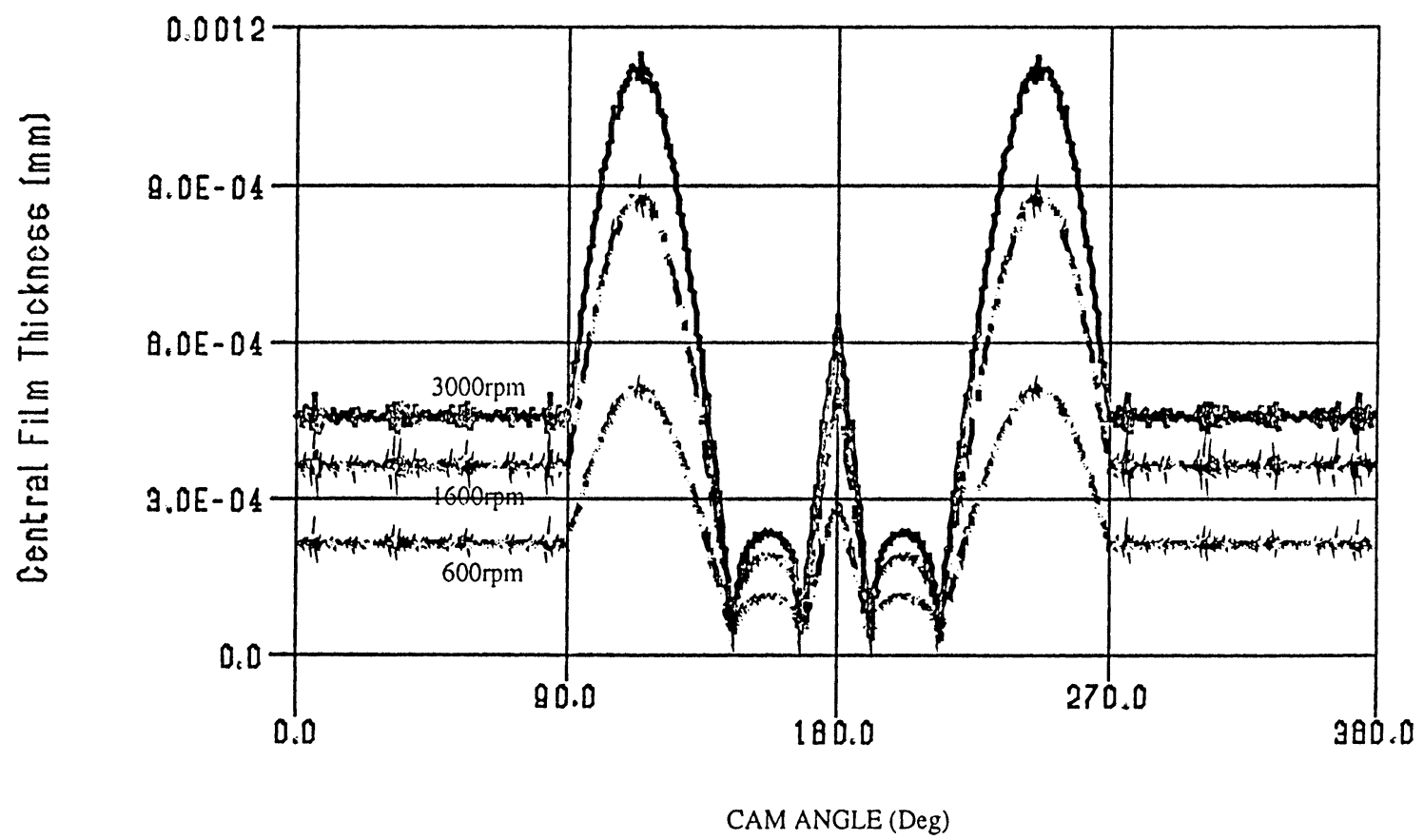

Fig. 7 Lubricant film thickness at different engine speeds 


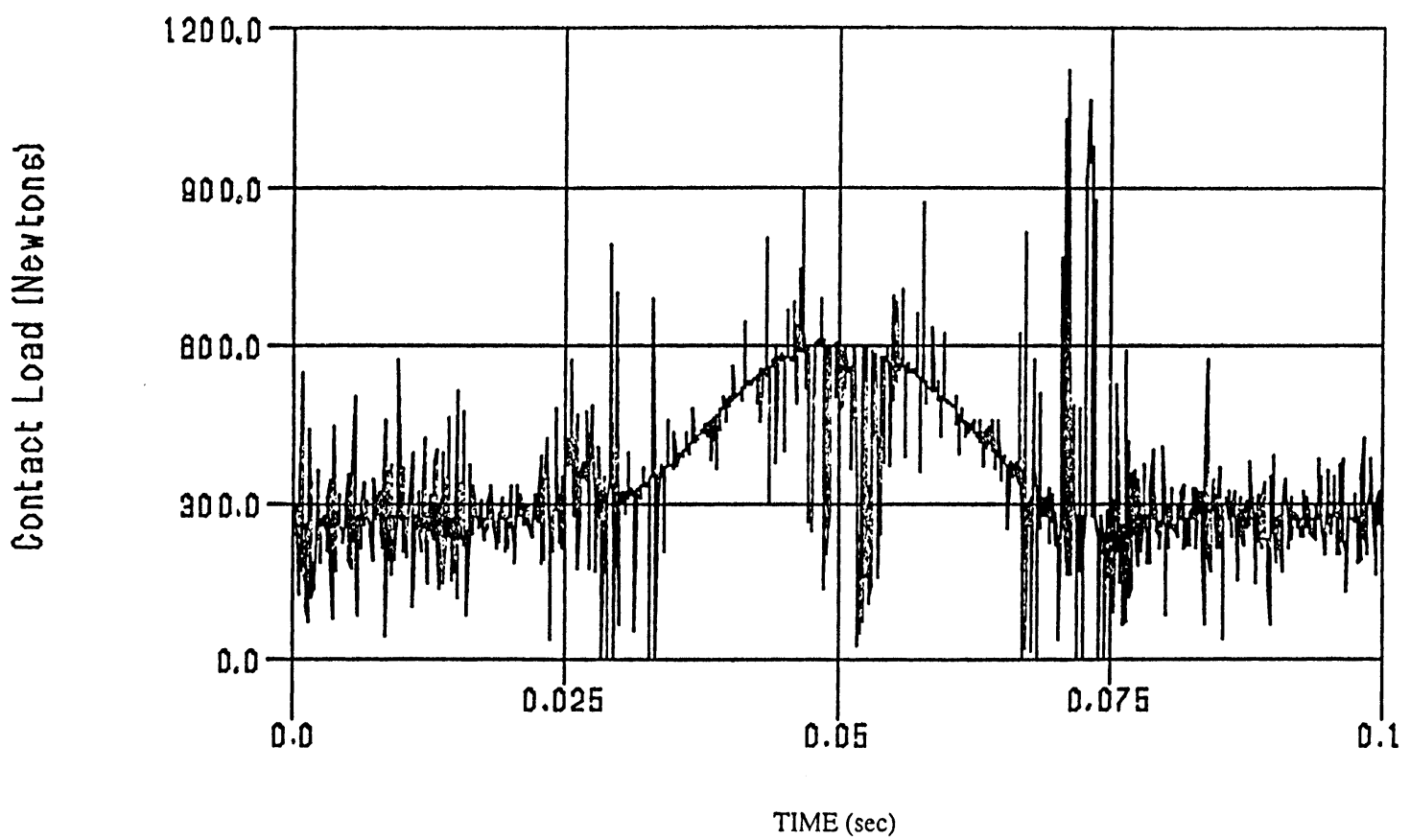

Fig. 8 Contact load variation at 600 r/min owing to camshaft elasticity

\section{REFERENCES}

1 Taylor, C. M. Fluid film lubrication in automobile valve trains. Proc. Instn Mech. Engrs, Part J, Journal of Engineering Tribology, 1994, 208(J4), 221-234.

2 Ciulli, E. A review of internal combustion losses. Part 1: specific studies on the motions of pistons, valves and bearings. Proc. Instn Mech. Engrs, Part D, Journal of Automobile Engineering, 1992, 206(D4), 223-226.

3 Eichhorn, U. and Schonfeld, H. The valve train of internal combustion engines as a source of vibrations-experimental results and methods of calculations. In Proceedings of 23rd FISITA Congress, Turin, Italy, May 1990, pp. 389395.

4 Rahnejat, H. Multibody Dynamics: Vehicles, Machines and Mechanisms, July 1998 (Professional Engineering Publications and Society of Automotive Engineers).

5 Hamilton, M. The hydrodynamics of a cam follower. Tribology Int., June 1980, 113-119.

6 Dyson, A. Kinematics and wear patterns of cam and finger follower automotive valve gear. Tribology Int., June 1980, 121-132.

7 Dowson, D., Taylor, C. M. and Zhu, G. A transient elastohydrodynamic lubrication analysis of a cam and follower. J. Phys. D; Appl. Phys., 1992, 25, 313-320.

8 Xiaolan, Ai. and Haiqing, Yu. A numerical analysis for the transient EHL process of a cam-tappet pair in I.C. Engine. Trans. ASME, J. Tribology, July 1989, 111, 413-417.

9 Rahnejat, H. Influence of vibration on the oil film in concentrated contacts. PhD thesis, Imperial College of Science and Technology, London, 1984.

10 Mostofi, A. and Gohar, R. Oil film thickness and pressure distribution in elastohydrodynamic point contacts. J. Mech. Engng Sci., 1982, 24(4), 173-182.
11 Johns, P. M. and Gohar, R. Roller bearings under radial and eccentric loads. Tribology Int., June 1981, 13, 131-136.

12 Johns, P. M. The design of cylindrical rollers for use in shafts and bearing systems. MSc thesis, Imperial College of Science and Technology, London, November 1978.

13 Rahnejat, H. and Gohar, R. Design of profiled taper roller bearing. Tribology Int., December 1979, 11, 269-275.

14 Mostofi, A. Oil film thickness and pressure distribution in elastohydrodynamic elliptical contacts. PhD thesis, Imperial College of Science and Technology, London, September 1981.

15 Roelands, C. J. A. Correlation aspects of viscositytemperature-pressure relationship of lubricating oils. $\mathrm{PhD}$ thesis, Delft University of Technology, The Netherlands, 1966.

16 Rahnejat, H. and Gohar, R. The vibrations of radial ball bearings. Proc. Instn Mech. Engrs. Part C, Journal of Mechanical Engineering Science, 1985, 199(C3), 181-193.

17 Mehdigoli, H., Rahnejat, H. and Gohar, R. Vibration response of wavy surfaced disc in elasto-hydrodynamic rolling contact. Wear, 1990, 139, 1-15.

18 Wijnant, Y. H. and Venner, C. H. Analysis of an EHL circular contact incorporating rolling element vibration. In Proceedings of 23rd Leeds-Lyon Symposium on Tribology, 1997, pp. 445-456 (Elsevier Science).

19 Kushwaha, M., Rahnejat, H., Jin, Z. M. and Johns, P. M. Tribo-multibody dynamic analysis of valve-train systems. In Proceedings of IMechE Conference on Multi-body Dynamics: New Techniques and Applications, London, December 1998, paper C/553, pp. 83-101 (Mechanical Engineering Publications, London).

20 Fessler, H. and Ham, R. Lubrication and stress analysis as a basis for camshaft optimisation. FISITA Congress, Turin, Italy, May 1990, pp. 565-579.

21 Kim, W. J., Jeon, H. S. and Park, Y. S. Contact force 
prediction and experimental verification on an $\mathrm{OHC}$ fingerfollower-type cam-valve system. Expl Mech., June 1981, $150-156$.

22 Reeve, J. Cams for Industry, 1997 (Mechanical Engineering Publications, London).

23 Williamson, B. P., Gaillard, I. R. and Benwell, S. Measurement of oil film thickness between a cam and bucket follower in a motored cylinder head. Part 1: Newtonian oils. In Proceedings of International Fuels and Lubricants Meeting and Exposition, Baltimore, Maryland, September 1989, SAE paper 892150, 1989, p. 11.

24 Kushwaha, M., Rahnejat, H. and Rahnejat, P. M. Tribodynamic multi-body analysis of vehicular valve-train systems. In Proceedings of ADAMS International Users' Conference 97 on Multi-body Dynamics, Yipsilanti, Michigan, May 1997, pp. 1-26.

25 Koster, M. P. Effect of flexibility of driving shaft on the dynamic behaviour of a cam mechanism. Trans. ASME, J. Engng for Industry, May 1975, 595-602.

\section{APPENDIX 1}

The Euler transformation matrix is

$$
[\mathbf{T}]=\left[\begin{array}{cccc}
\mathrm{C} \psi \mathrm{C} \phi & -\mathrm{C} \psi \mathrm{S} \phi & \mathrm{S} \psi \mathrm{S} \theta & 0 \\
-\mathrm{S} \psi \mathrm{C} \theta \mathrm{S} \phi & -\mathrm{S} \psi \mathrm{C} \theta \mathrm{C} \phi & & \\
\mathrm{S} \psi \mathrm{C} \phi & -\mathrm{S} \psi \mathrm{S} \phi & & \\
+\mathrm{C} \psi \mathrm{C} \theta \mathrm{S} \phi & +\mathrm{C} \psi \mathrm{C} \theta \mathrm{C} \phi & -\mathrm{C} \psi \mathrm{S} \theta & 0 \\
\mathrm{~S} \theta \mathrm{S} \phi & \mathrm{S} \theta \mathrm{C} \phi & \mathrm{C} \theta & 0 \\
0 & 0 & 0 & 1
\end{array}\right]
$$

where $\mathrm{C} \equiv \cos , \mathrm{S} \equiv \sin$. 


\section{APPENDIX 2}

The generalized inertial submatrix for each part in the multi-body model is as follows:

$$
\left[\begin{array}{ccccccccccccccc}
m \alpha & 0 & 0 & 0 & 0 & 0 & 0 & 0 & 0 & 0 & 0 & 0 & 0 & 0 & 0 \\
0 & m \alpha & 0 & 0 & 0 & 0 & 0 & 0 & 0 & 0 & 0 & 0 & 0 & 0 & 0 \\
0 & 0 & m \alpha & 0 & 0 & 0 & 0 & 0 & 0 & 0 & 0 & 0 & 0 & 0 & 0 \\
0 & 0 & 0 & 1 & 0 & 0 & 0 & 0 & 0 & -\alpha & 0 & 0 & 0 & 0 & 0 \\
0 & 0 & 0 & 0 & 1 & 0 & 0 & 0 & 0 & 0 & -\alpha & 0 & 0 & 0 & 0 \\
0 & 0 & 0 & 0 & 0 & 1 & 0 & 0 & 0 & 0 & 0 & -\alpha & 0 & 0 & 0 \\
1 & 0 & 0 & 0 & 0 & 0 & -\alpha & 0 & 0 & 0 & 0 & 0 & 0 & 0 & 0 \\
0 & 1 & 0 & 0 & 0 & 0 & 0 & -\alpha & 0 & 0 & 0 & 0 & 0 & 0 & 0 \\
0 & 0 & 1 & 0 & 0 & 0 & 0 & 0 & -\alpha & 0 & 0 & 0 & 0 & 0 & 0 \\
0 & 0 & 0 & 0 & 0 & 0 & 0 & 0 & 0 & -a_{1} \alpha & -a_{2} \alpha & -a_{3} \alpha & 1 & 0 & 0 \\
0 & 0 & 0 & 0 & 0 & 0 & 0 & 0 & 0 & -b_{1} \alpha & -b_{2} \alpha & 0 & 0 & 1 & 0 \\
0 & 0 & 0 & 0 & 0 & 0 & 0 & 0 & 0 & -c_{1} \alpha & 0 & -c_{3} \alpha & 0 & 0 & 1 \\
0 & 0 & 0 & 0 & 0 & 0 & 0 & 0 & 0 & 0 & 0 & 0 & \alpha & 0 & 0 \\
0 & 0 & 0 & 0 & 0 & 0 & 0 & 0 & 0 & 0 & 0 & 0 & 0 & \alpha & 0 \\
0 & 0 & 0 & 0 & 0 & 0 & 0 & 0 & 0 & 0 & 0 & 0 & 0 & 0 & \alpha
\end{array}\right]
$$

where $\alpha=s_{\mathrm{c}} / \Delta t, s_{\mathrm{c}}$ being the scaling factor (usually having a value of 1 ), and

$$
\begin{aligned}
& a_{1}=I_{x x} \mathrm{~S}^{2} \theta_{k} \mathrm{~S}^{2} \phi_{k}+I_{y y} \mathrm{~S}^{2} \theta_{k} \mathrm{C}^{2} \phi_{k}+I_{z z} \mathrm{C}^{2} \theta_{k} \\
& a_{2}=\left(I_{x x}-I_{y y}\right) \mathrm{S} \theta_{k} \mathrm{~S} \phi_{k} \mathrm{C} \phi_{k} \\
& a_{3}=I_{z z} \mathrm{C} \theta_{k} \\
& b_{1}=a_{2} \\
& b_{2}=I_{x x} \mathrm{C}^{2} \phi_{k}+I_{y y} \mathrm{~S}^{2} \phi_{k} \\
& c_{1}=I_{z z} \mathrm{C}^{2} \theta_{k} \\
& c_{3}=I_{z z} \mathrm{C} \theta_{k}
\end{aligned}
$$

where $k$ denotes the part number. The vector of unknowns is $\left\{\begin{array}{lllllllllllllll}u & v & w & \omega_{\psi} & \omega_{\theta} & \omega_{\phi} & x & y & z & \psi & \theta & \phi & M_{\psi} & M_{\theta} & M_{\phi}\end{array}\right\}^{\mathrm{T}}$ 


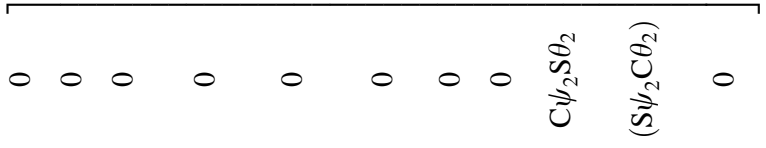

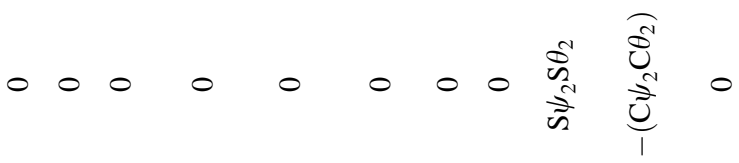

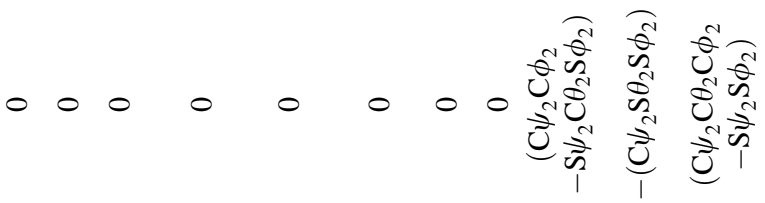

$$
\begin{aligned}
& 0000000-0 \frac{\sqrt{3}}{\sqrt{2}} 0
\end{aligned}
$$

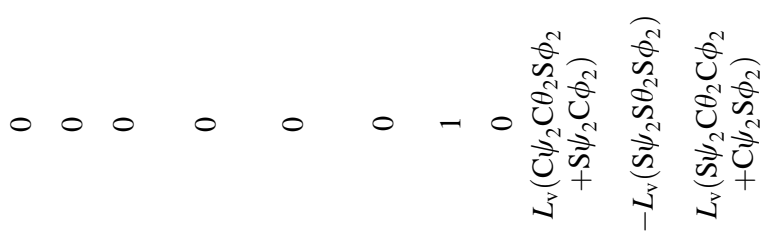

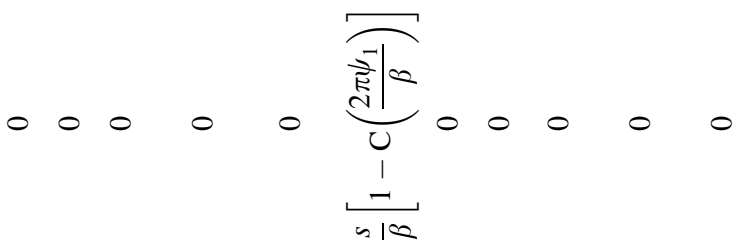

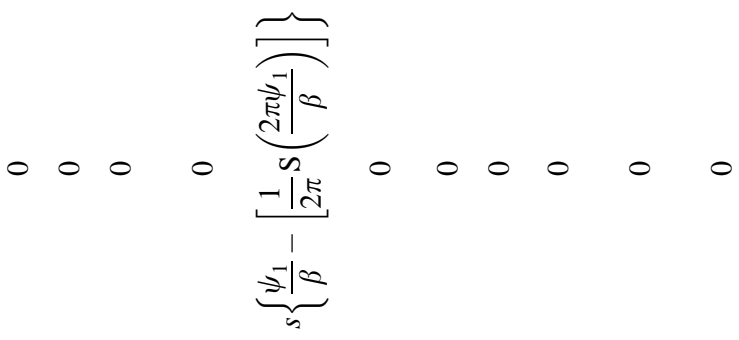

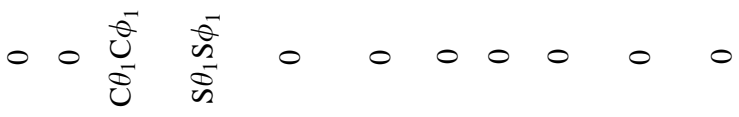

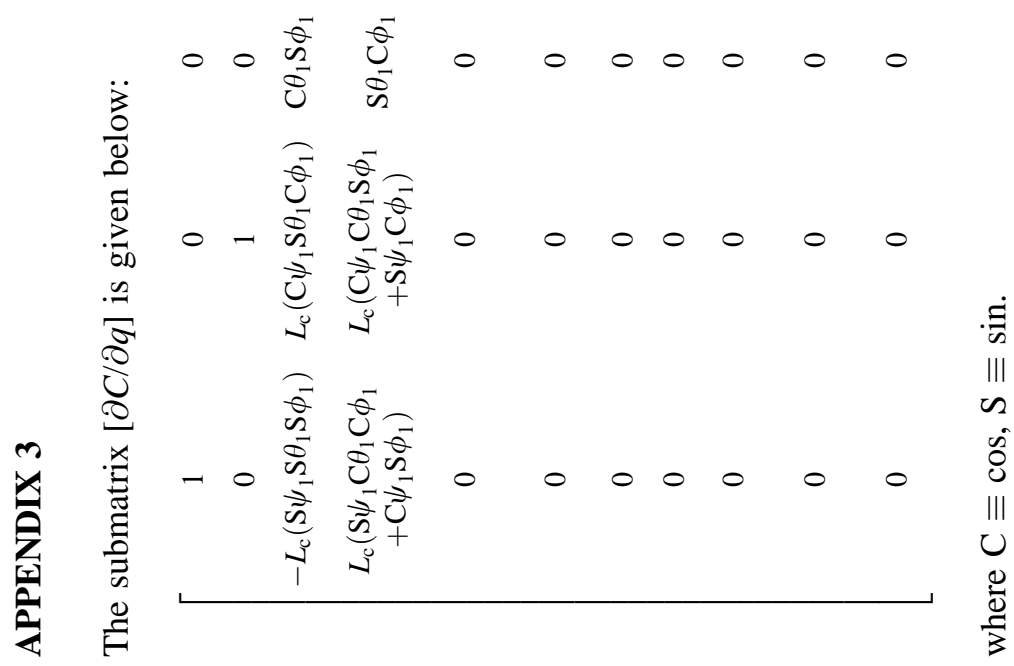

